\title{
The Design on the Comprehensive Utilization Exhibition System of New Energy Automatic Control System
}

\author{
Xiaofeng $\mathrm{Li}^{1, \mathrm{a}}$ \\ ${ }^{1}$ Tianjin Maritime College, Tianjin, China
}

\begin{abstract}
In this paper, the construction of a set of comprehensive utilization of new energy system is put forward. The system can show the real time operation and simulated the actual system of the solar photovoltaic system, the solar-thermal systems and the air source heat pump water heater. And according to the running condition, energy saving and reduce carbon emissions for each new energy application situation can be calculated comparing to using traditional energy. Another reserved interface, which can be for the subsequent construction of other new energy systems (such as ground source heat pump system) is provided. This paper introduces the design scheme of the comprehensive utilization of new energy system.
\end{abstract}

\section{Introduction}

With the development of the economy, it faces two major problems in energy and the environment in the 21 st century. China has now become the world's largest energy consumer and has promoted the application of high-tech, intelligent, efficient and clean new energy systems to obtain a sustainable economic system and relieve the tension of energy using [1]. The innovative strategy will not only enhance China's soft power, but also provide a broad and long-term new external market for the newly developed intelligent green energy technology in 21st, enabling China to enter the new energy era faster [2].

New energy generally refers to renewable energy developed on the basis of new technologies, including solar energy, biomass energy, wind energy, geothermal energy, wave energy, ocean current energy and tidal energy, and thermal cycling between the ocean surface and deep layers. In addition, there are hydrogen energy, biogas, alcohol, methanol, etc. The widely energy sources used such as coal, oil, natural gas, and water energy are called conventional energy sources.

Nowadays, the use of new energy is becoming more and more abundant. Many green buildings are no longer satisfied with the application of only one new energy form in design and construction. Most buildings use a variety of new or renewable energy sources to complement each other and maximize the advantages of every new energy. In response to this situation, this paper designs a variety of new energy comprehensive utilization automatic control system.

\section{The functions of new energy comprehensive utilization automatic control system}

The new energy comprehensive utilization automatic control system uses the data acquisition system to collect real-time operational data of new energy utilization modules such as solar thermal utilization system, solar photovoltaic system and air source heat pump system. These data can provide basis data for operation management. Secondly, these real-time data can be transmitted to the integrated control center through the Internet, and the collected data can be analyzed by using an automatic control system, according to different solar sunshine, water temperature, underground temperature, air temperature, etc. to control the opening ,closing, increasing or decreasing of the every system and maximize the savings of conventional energy (see Figure 1). The system also calculates the amount of energy saving per system, the amount of energy saving of the integrated system, and the amount of carbon dioxide emission reduction compared to the conventional systems that can be utilized. The new energy comprehensive utilization automatic control system needs to achieve the following functions:

\footnotetext{
a Corresponding author: lixiaofeng404@163.com
} 


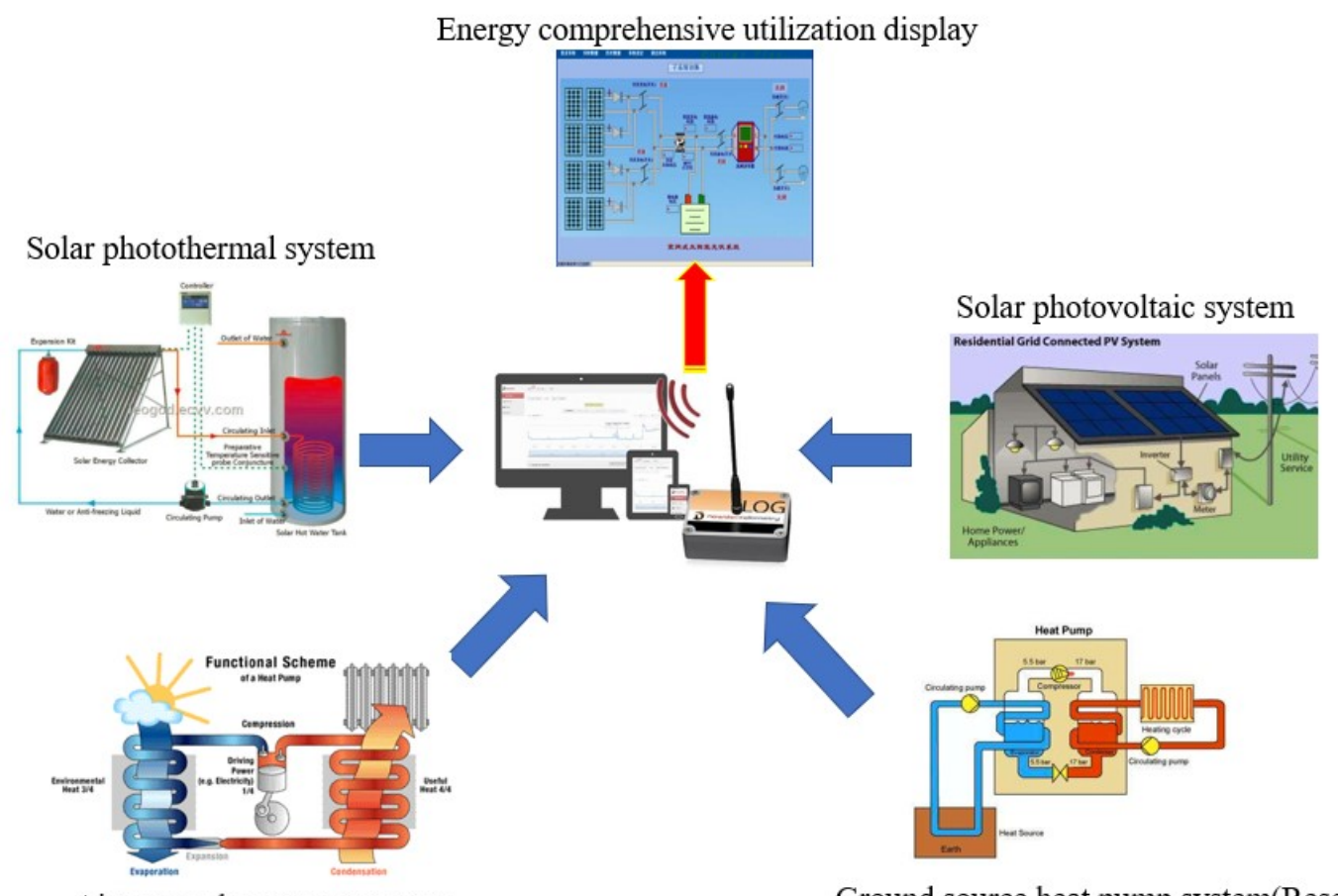

Air source heat pump system

Ground source heat pump system(Reserved)

Figure 1. System diagram of the new energy comprehensive utilization automatic control system.

1. The system can be connected to the actual application of air energy heat pump system, solar thermal energy, and solar photovoltaic system through the internet, and display the real-time data of various energy utilization conditions (air temperature, solar radiation intensity, hot water temperature, flow, cooling capacity, power generation, energy consumption, etc.). Through the monitoring and analyzing these data of each system, it is possible to calculate the energy saving situation of each system running separately or in combination, and calculate the ratio of application new energy. It also can calculate the reduction in carbon emissions from the application of new energy sources over traditional energy sources. All those operational data and energy analysis calculation data is showed on the LED screen.

2. A set of simulation software for pure software simulation of the operation of several new energy systems is established. According to the process operation diagrams and parameters of each new energy system, this simulation software needs to simulate and calculate this parameters, and mathematical modelling and related algorithms are established. Several new energy systems can be simulated by signal, and the equipment capacity, season data, production, energy using, energy conservation and emission reduction of simulating new energy devices can be realized, which can be used for teaching demonstration or research.

3 . Since the types and quantities of new energy used in each building are different, it is possible to introduce the new energy systems in the future, such as ground source heat pumps. Therefore, a reserved system interface is installed. This reserved interface can only be limited to the reserved monitoring board in the hardware monitoring cabinet. If the interface is put into use in the future, only the further process design needs to be improved on the basis of the reserved board.
4. On the basis of the actual project operation site, the system can be debugged according to the data from the monitoring system.

5. The display interface scroll display function can be realized by the displaying expansion card. It can be displayed between the floor plan of each floor of the building, each new energy system and the energy-saving parameters of the comprehensive utilization system. By designing the touch screen monitoring interface, the touch screen is provided with a guide and navigation function, and has a locking and protection means (a dedicated lock case).

\section{Schematic design of the new energy comprehensive utilization automatic control system}

\subsection{Design steps of new energy comprehensive utilization automatic control system}

According to the functions that need to be realized, the whole new energy comprehensive utilization automatic control system includes at least the data monitoring and analysis systems of three new energy systems: air energy heat pump system, solar light heat system and solar photovoltaic system, and a reserved data collection interfaces for the follow-up new energy utilization system need to be provided. Each subsystem contains both software simulation runs and actual engineering operations. The construction of the entire system is divided into three phases:

The first stage: three sets of on-site controllers and three touch screens are provided for the three systems according to the process operation monitoring points. The 
preliminary design of touch screens for air energy heat pump water heater systems, solar thermal systems and solar photovoltaic systems is done. A simulated touch screen interface and pure simulation software system are built, and the frame of the actual engineering system operation monitoring software is designed.

The second stage: The corresponding monitoring system, software and hardware are designed for three different systems. The corresponding sensor, actuator, control cabinet and other hardware monitoring facilities are purchased; The construction transformation on specific engineering sites of three different systems are carried out.

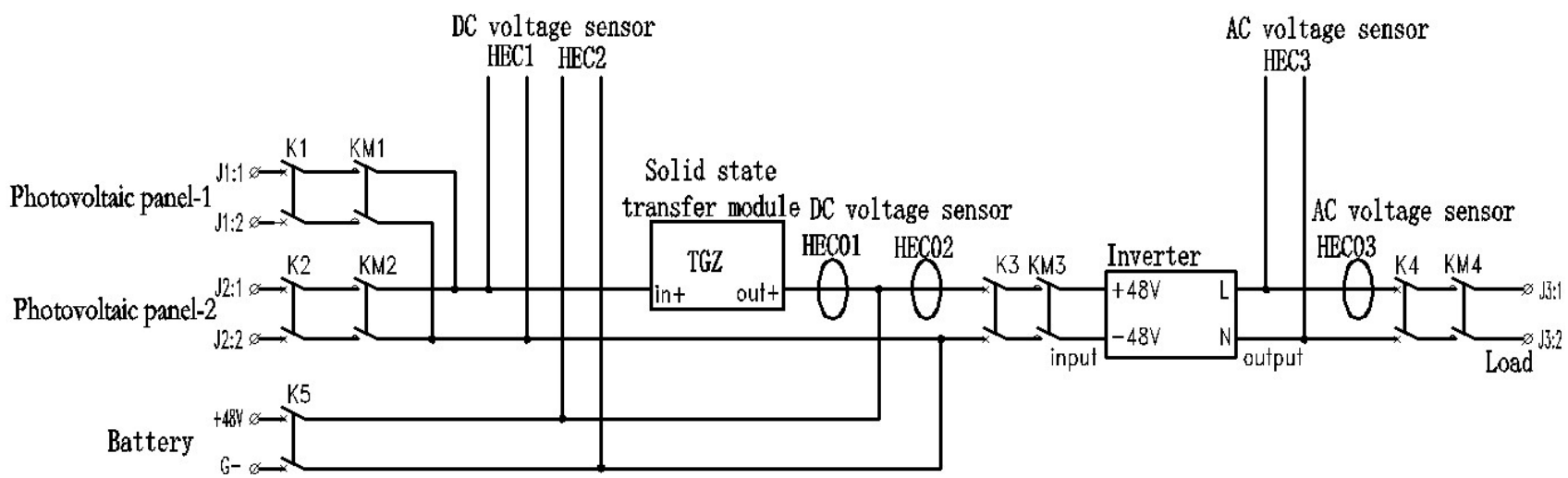

The third stage: On the basis of the second stage, the touch screen design of the monitoring system and the software system are implemented. the whole set of the new energy comprehensive utilization automatic control system is debugged, and finally the system is reliably operated reliably.

\subsection{Design of the new energy comprehensive utilization automatic control system} detailed design of the actual operation monitoring

Figure 2. The schematic diagram of the photovoltaic power generation system.

Figure 2 shows the schematic diagram of the photovoltaic power generation system. According to the system schematic diagram, the system can be connected to two sets of photovoltaic power generation boards. The direct current generated by the photovoltaic effect can be stored directly in the battery or enter the inverter through the photovoltaic discharge switch. The inverter converts the direct current into alternating current, and then accesses the load, which is the electrical equipment, to use the generated alternating current. In this system, the DC voltage, DC current, AC voltage, AC current, battery voltage and other data can be measured by the sensor, and transmitted to the control center. The data is analyzed to control of each switch.

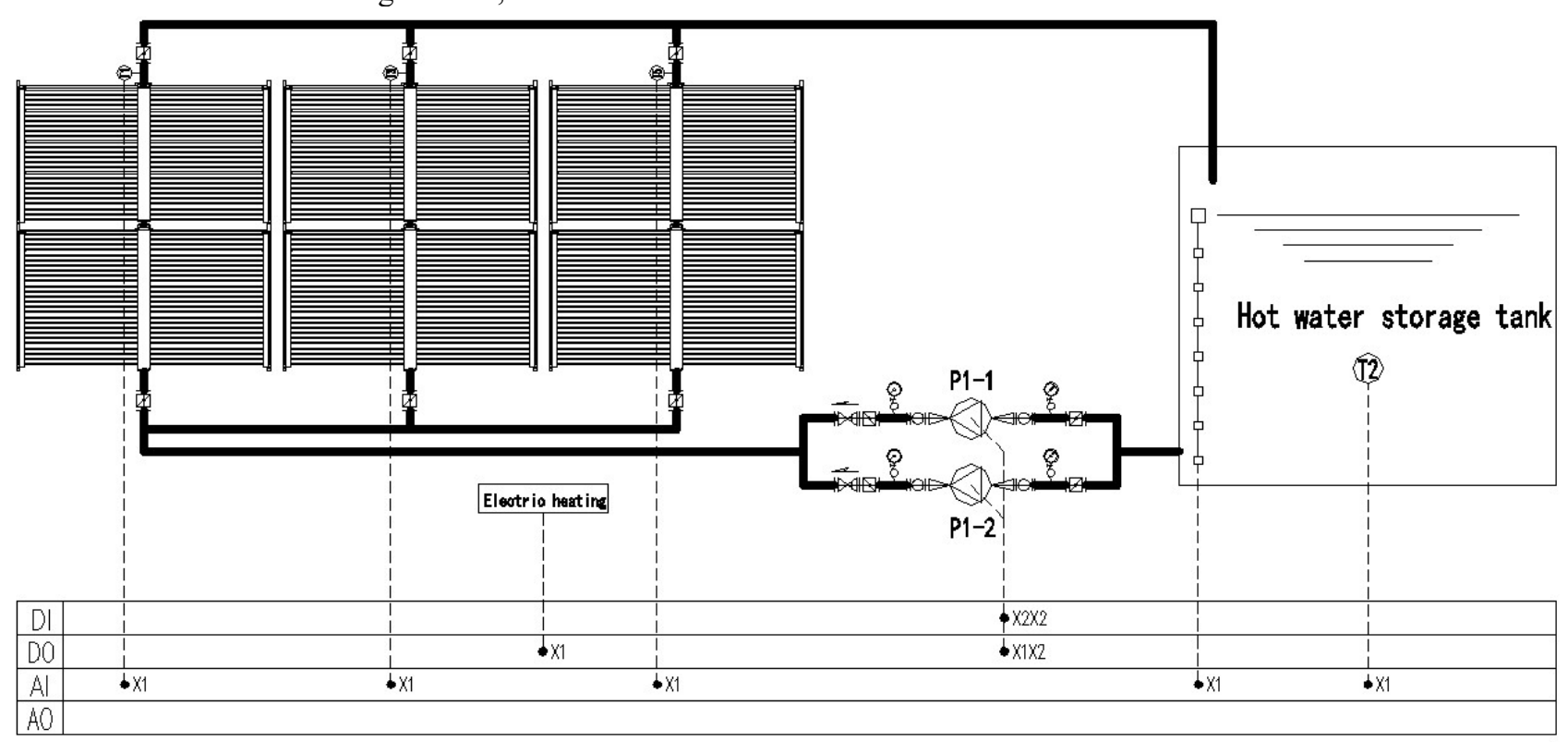

Figure 3. The schematic diagram of the solar thermal system.

A schematic diagram of the solar thermal system is shown in figure 3. It can be seen that the three sets of solar thermal panels can absorb solar energy and put the heat energy into the water. The water heated enters the 
hot water storage tank and then enters the thermal equipment. If the water temperature drops, or there is supplemental cold water to the tank, the cold water is pumped into the solar thermal panel to continue heating. In this system, the temperature sensor is used to measure the inlet and outlet water temperature of the water tank, the average temperature in the water tank, the water temperature of the inlet and outlet of the solar thermal panel, and so on. These data can be transmitted to the control center and be analyzed to realize automatic control of the entire system.

Figure 4 is a schematic diagram of an air energy heat pump system, which is similar to a photothermal system except that the solar thermal plate is replaced with an air energy heat pump system.

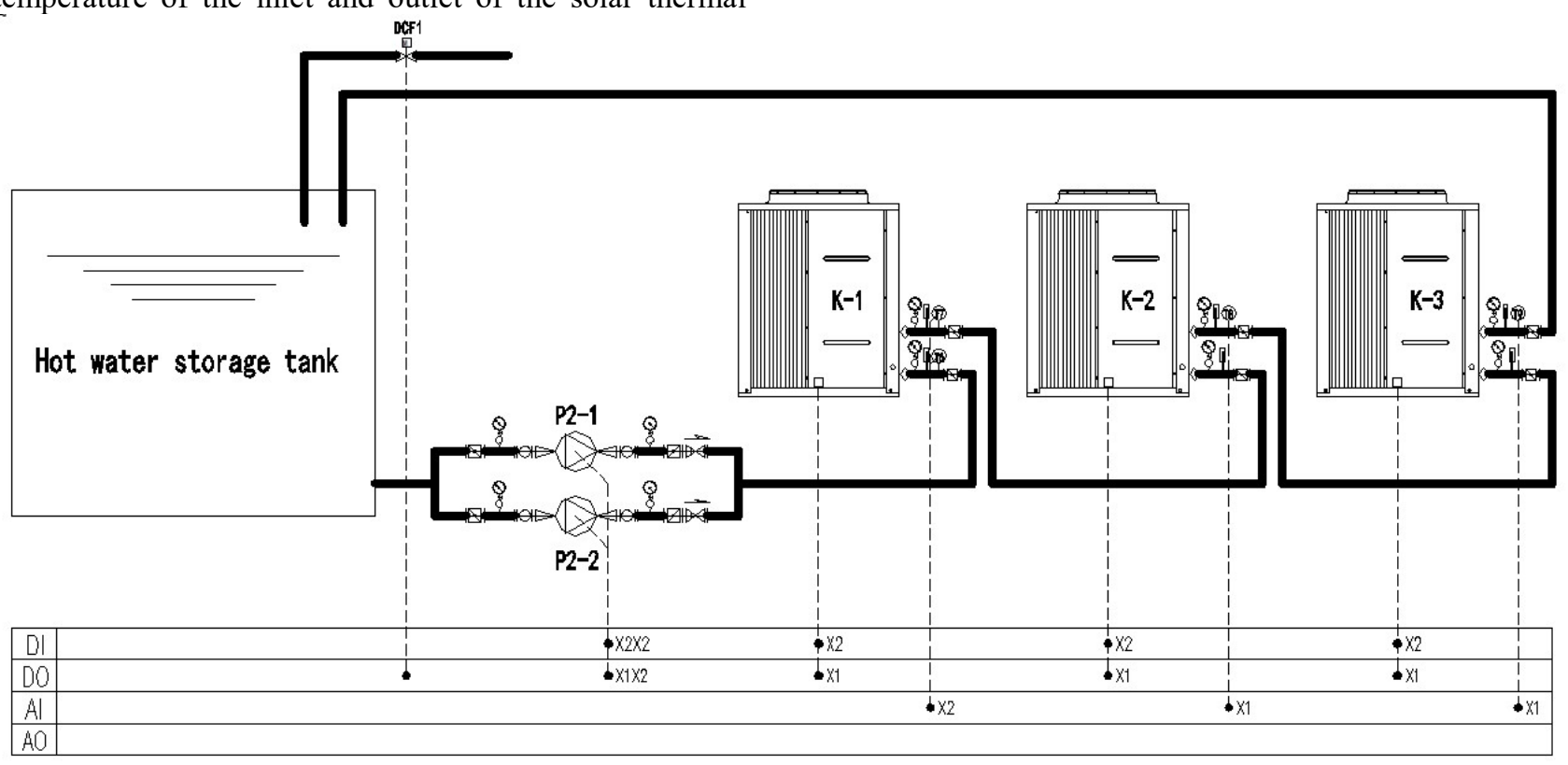

Figure 4. The schematic diagram of an air energy heat pump system.

\section{Conclusion}

The new energy comprehensive utilization automatic control system will demonstrate the real-time parameters, operating conditions, and energy savings compared to using the traditional energy sources for new energy applications such as solar thermal utilization systems, air source heat pump systems, solar photovoltaic systems, and ground source heat pump systems in the future. This kind of the system has no molded products in the market. Through procurement, design, installation, commissioning and operation, the real-time operation status, energy saving situation and carbon emission reduction can be realized, and a port can be reserved to provide a display platform for other new energy construction. This paper mainly introduces the function of the new energy comprehensive utilization automatic control system and the design of the system.

\section{References}

1. Hailong Zhang, Research on the new development in Chian, PhD thesis of Jilin University, (2014.12).

2. Robert A. Hefner III, Big energy transformation, (2013). 